\title{
Bidirectional comorbidity between bipolar- and obsessive-compulsive disorders: symptoms frequency, treatment challenges and underexplored areas.
}

\author{
Trino Baptista ${ }^{1}$, Lisette Galué and Fabiola Martínes $^{2}$ \\ ${ }^{1}$ Deparment of Physiology, Universidad de Los Andes Medical School, Mérida, Venezuela. \\ ${ }^{2}$ Department of Psychiatry, Universidad de Los Andes Medical School, Mérida, Venezuela.
}

Key words: categorical diagnosis; comorbidity; mood disorders; obsessive- compulsive disorders; symptoms frequency.

Abstract. The high comorbidity of bipolar- (BD) and obsessive-compulsive disorder (OCD) is a challenge in the psychiatric field. This topic has been searcely investigated in Latin America, and we could not find published studies conducted in Venezuela. Given the common difficulty to establish a categorical diagnosis in comorbid conditions, we assessed the frequency of current OC symptoms (OCS) in subjects with primary BD, and of BD symptoms (BDS) in subjects with primary OCD. We administered the Yale-Brown Obsessive-Compulsive Scale (Y-BOCS) to 40 patients with BD, and the Young Mania Rating Scale (YMRS) and the Mood Disorder Questionnaire (MDQ) to 42 patients with OCD. We observed clinically significant OCS (Y-BOCS score $\geq 16$ ) in $20 \%$ of BD subjects, and current hypomania or mania in $16.7 \%$ and $19 \%$ of OCD patients respectively. A significant positive correlation between age and YMRS was detected in OCD females, $\mathrm{p}=0.04$. We here confirmed the high comorbidity in the bipolar and obsessive-compulsive dimensions. Numerous studies identify the clinical burden, diagnostic difficulties and treatment intricacy of this comorbidity, which warrants for further research to assist this sensible population. We illustrate the challenges of pharmacological and psychological treatment, and the issue of family history of psychopathology, with two conspicuous clinical vignettes extracted from the studied sample. 


\title{
Comorbilidad bidireccional entre los trastornos bipolar y obsesivo-compulsivo: frecuencia de sintomas, retos en el tratamiento y áreas sub-exploradas.
}

\author{
Invest Clin 2020; 61 (3): 189-195
}

Palabras clave: comorbilidad; frecuencia de síntomas; trastornos del humor; trastorno obsesivo compulsivo.

Resumen. La alta comorbilidad entre el trastorno bipolar (TB) y el trastorno obsesivo compulsivo (TOC) es un reto para la psiquiatría. Este tema ha sido poco investigado en América Latina, y no encontramos publicaciones de estudios realizados en Venezuela. Dada la dificultad para realizar diagnósticos categóricos en condiciones de comorbilidad, evaluamos la frecuencia de síntomas obsesivo-compulsivos (SOC) actuales, en sujetos con TB primario, y síntomas actuales de trastorno bipolar (STB) en sujetos con TOC primario. Aplicamos la Escala para la Evaluación del TOC de Yale-Brown (Y-BOCS) a 40 pacientes con TB, y la Escala para la Evaluación de Manía Young (YMRS) y el Cuestionario de Trastornos del Humor (MDQ) a 42 pacientes con TOC. Detectamos SOC con significación clínica (puntuación en el Y-BOCS $\geq 16$ ) en $20 \%$ de los sujetos con TB, e hipomanía o manía actual en 16,7\% y 19\% respectivamente, en pacientes con TOC. Detectamos una correlación positiva significativa entre la edad y las puntuaciones en la YMRS en mujeres con TOC, $\mathrm{p}=0,04$. Confirmamos la alta comorbilidad en las dimensiones del TB y del TOC. Numerosos estudios han identificado la carǵa clínica, y las dificultades diaǵnósticas y terapéuticas de esta comorbilidad, la cual requiere investigaciones adicionales para asistir a esta población clínica tan sensible. Finalmente, ilustramos los retos en el tratamiento farmacológico y psicológico y la historia familiar de psicopatología, con dos viñetas clínicas representativas, extraídas de la muestra en estudio.

Received: 18-02-2020 Accepted: 08-05-2020

\section{INTRODUCTION}

The lifetime prevalence of obsessivecompulsive disorder (OCD) is 2.3\% (1). When considering bipolar I and bipolar II disorders (BD), the prevalence is $1.0 \%$ and $1.1 \%$ respectively (2).

A high co-occurrence of $\mathrm{BD}$ and $\mathrm{OCD}$ was earlier reported (3) and has been consistently confirmed. The life-time prevalence of BD-I or BD-II in OCD is 3.9\% and $13.5 \%$ respectively, whereas the prevalence of $\mathrm{OCD}$ in BD-I is $21.7 \%$ (4). Both disorders could share some pathogenic mechanisms.
Comorbidity is an issue for categorical diagnosis in psychiatry. The DSM-III to-V criteria do not exclude BD or OCD in the same individual. Besides, OCD frequently coexists with schizophrenia $(5,6)$. However, the authors of the last DSM version (DSM-V) emphasize that it is seientifically premature to propose alternative definitions for most disorders (7). It is thus, a substitute method, to refer to "symptoms" instead of "disorder" for the secondary diagnose. This is common when assessing the association between psychosis and OCD $(5,6)$, but is less reported for BD-OCD comorbidity. 
Regarding the onset of symptoms, studies report either $\mathrm{BD}-\mathrm{OCD}$ beginning concomitantly; BD-OCD cycling together; OCD preceding $\mathrm{BD}$ onset, or depressive episodes before the onset of OCD (8).

Previous studies show that compared to BD alone, patients with OCD-BD may have a higher number of depressive episodes, suicidal thoughts, substance and alcohol use, attention-deficit/hyperactivity- and oppositional disorder, rates of personality disorders and hospitalizations (8). Subjects with OCD-BD comorbidity may also display an episodic course of OC symptoms (OCS) compared to the pattern in OCD alone (8). There is also a notable paucity of studies in Latin America (9-11), and we could not find any publication about studies conducted in Venezuela on this topic. There is also a need in the field of optimal psychotherapeutic interventions.

We thus report the frequency of $\mathrm{BD}$ symptoms (BDS) in subjects with primary OCD, and of OCS in patients with primary BD. Besides, we present two Clinical Vignettes that illustrate current challenges for the management of these conditions.

\section{SUBJECTS AND METHODS}

We conducted this study in the outand inpatient clinies of Universidad de Los Andes, University Hospital, Mérida, Venezuela, from December 2018 to June 2019. The Ethics Committee of the Hospital approved the protocol, which required the subjects' verbal consent of voluntary participation.

The inclusion/exclusion criteria were: a) to be older than 18 years; b) to be registered in the Psychiatric Unit with the diagnosis of $\mathrm{BD}$ or $\mathrm{OCD}$, and; $\mathrm{c}$ ) to be able to go through a one-two hour interview.

We evaluated consecutively admitted patients with a primary diagnosis of $\mathrm{BD}$ or OCD, and verified these diagnoses with the Structured Clinical Interview for DSM-IV Axis Disorders (12).

\section{Procedure}

Subjects with primary OCD disorder answered the Spanish version of the Young Mania Rating Scale (YMRS) (13) and a validated version in Mérida, Venezuela by Araque (14), of the Mood Disorder Questionnaire (MDQ) for the diagnosis of mania or hypomania during the week before the evaluation. The cut-off points of the YMRS were absent $\leq 6$; sub-clinical $7-11$; hypomania $\geq 12$; mania $\geq$ 20 (13).

Primarily diagnosed BD subjects answered the Spanish version of the Yale-Brown Obsessive-Compulsive Scale (YBOCS), with the following cut-off points for the OCS severity for the previous week: 0-7 absent; 8-15 mild; 16-23 moderate; 24-31 severe; 32-40 extreme (15). We considered a score $\geq 16$ as clinically significant (16).

We did not attempt to diagnose OCD in subjects with $\mathrm{BD}$, or $\mathrm{BD}$ in subjects with OCD according to the categorical DSM-IV criteria, because patients and relatives tend to mix the memories of early OCS and affective symptoms, particularly in remote episodes. This fact, very often precludes the clinicians' agreement about which is the primary diagnosis according to strict categorical diagnosis, such as those required in the DSM criteria (7).

\section{Statistical analysis}

We used the IBM-SPSS-20 program. Student $t$ test, the Mann-Whitney U test, chi-square and bivariate correlation analysis were considered significant when $\mathrm{p} \leq 0.05$.

At the end of the Discussion section, we present two clinical vignettes that illustrate the clinical burden and challenges in treatment in comorbid patients.

\section{RESULTS}

We evaluated 40 subjects with primary $\mathrm{BD}$ and 42 with primary OCD (Tables I and II). In the primary BD group (Table I), 65\% were females and $35 \%$ had BD-II. The BD-II type group was significantly older than the 
TABLE I

OBSESSIVE-COMPULSIVE SYMPTOMS IN SUBJECTS WITH PRIMARY BIPOLAR DISORDER.

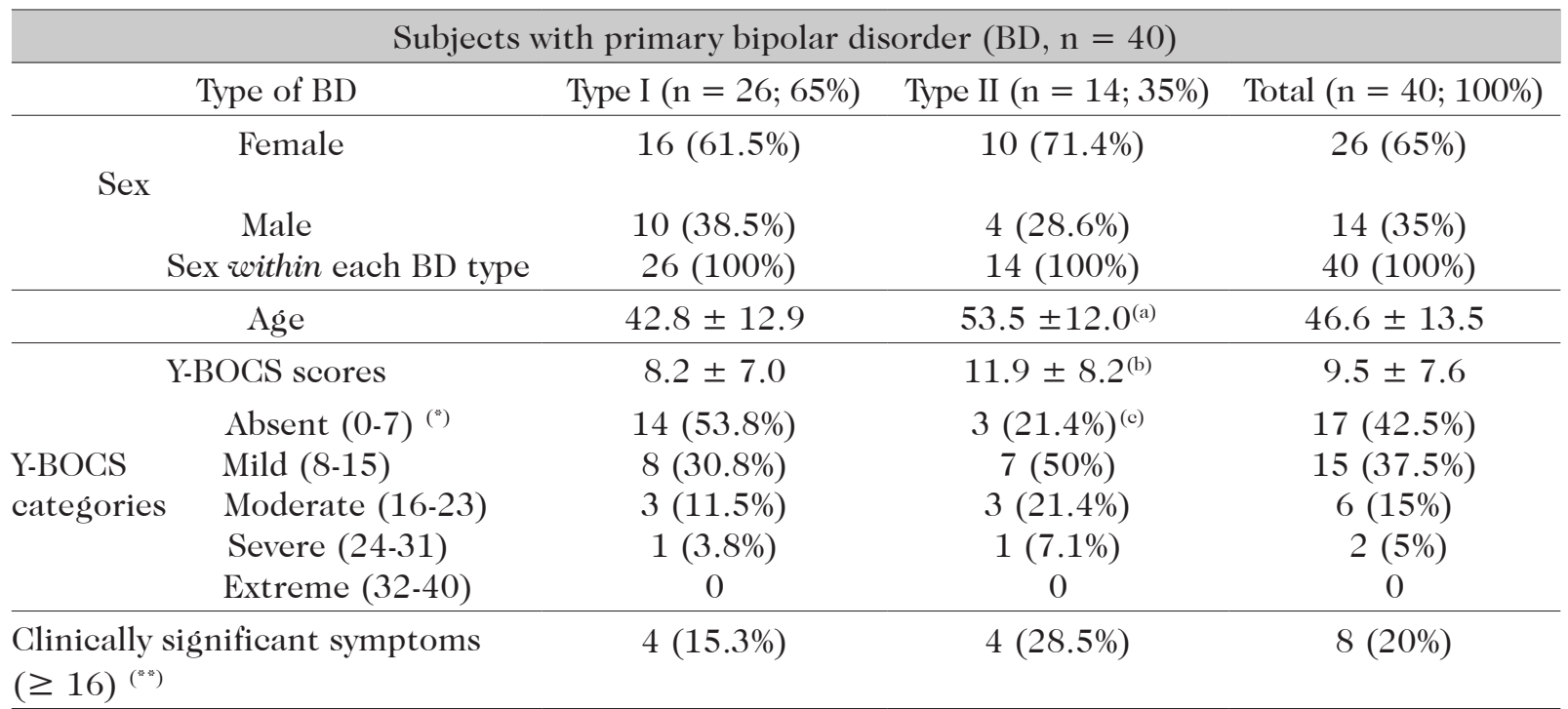

Age (years) and Y-BOCS scores are described as mean \pm standard deviations; (a) $\mathrm{t}(38)=2.6, \mathrm{p}=0.01$; (b) $\mathrm{t}(38)=$ $1.5 \mathrm{p}=0.15$; (c) $\chi^{2}(1)$ with contiguity correction, grouping "absent" vs. "all other categories" $=2.7, \mathrm{p}=0.1$ (" and *) = categories according to refs. (13) and (16) respectively.

\section{TABLE II}

BIPOLAR DISORDER SYMPTOMS IN SUBJECTS WITH PRIMARY OBSESSIVE-COMPULSIVE DISORDER.

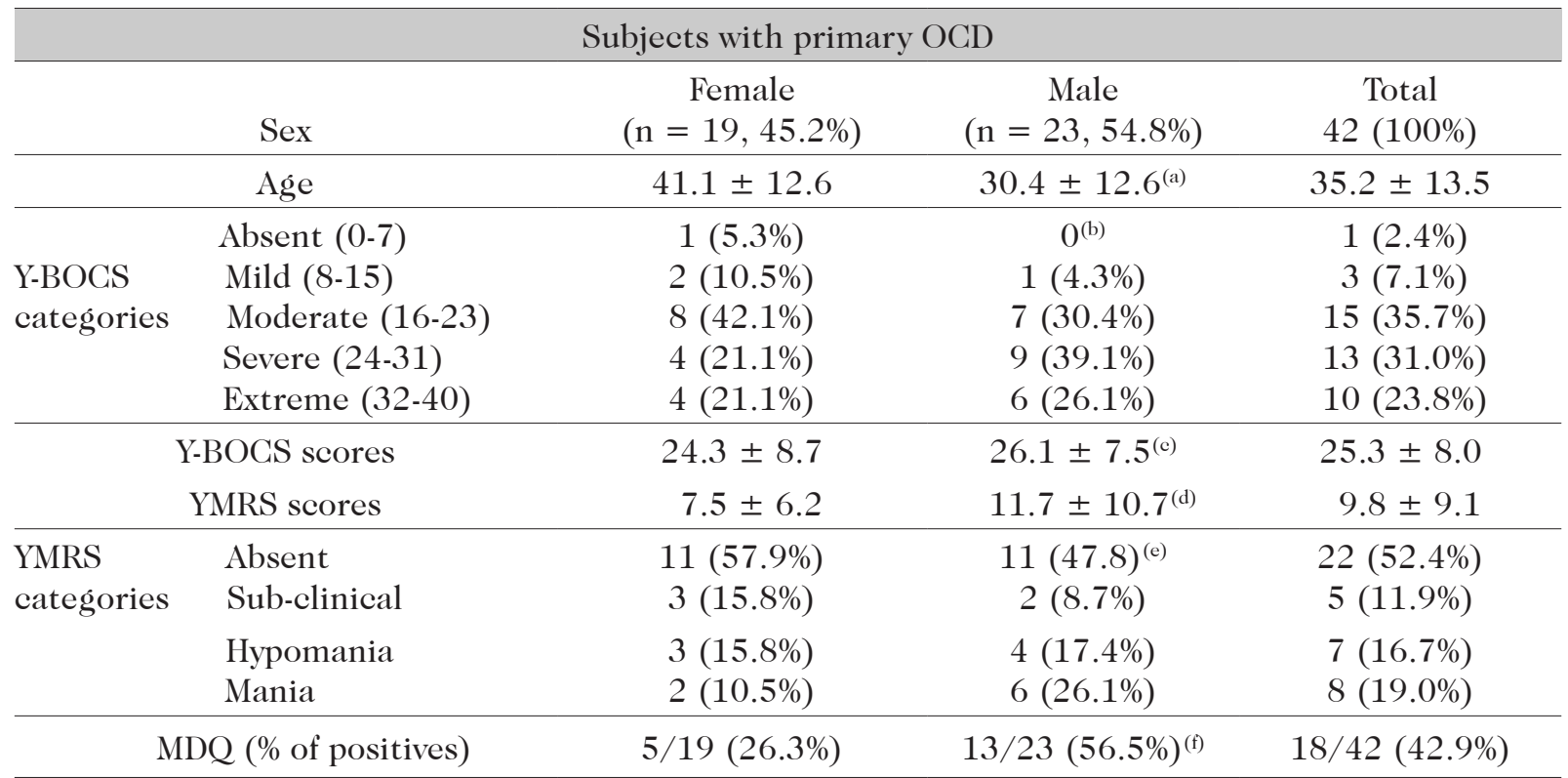

(a) $\mathrm{t}(40)=2.7, \mathrm{p}=0.01$; (b) $\chi^{2}$ (1) with contiguity correction, grouping "absent + mild + moderate" vs. "severe + extreme" categories $=1.4, \mathrm{p}=0.2 ;(\mathrm{c}) \mathrm{t}(40)=0,1 . \mathrm{p}=0.5 ;$ (d) Mann-Whitney U test, $\mathrm{p}=0.4$; (e) $\chi^{2}$ (1) with contiguity correction, grouping "absent + sub-clinical" vs. "hypomania + mania" categories $=0,7, \mathrm{p}=0,4 ;(\mathrm{f}) \chi^{2}$ (1) with contiguity correction $=2.7, \mathrm{p}=0.09$. 
type I. The type II group displayed higher, not statistically significant scores in the YBOCS than the type I. Considering the YBOCS categories, type II subjects showed a lower frequency of the "absent" categories, and higher frequencies of mild, moderate and severe frequencies than the type I group; this figure reached marginal statistical significance. As a whole, the BD group showed $20 \%$ of moderate-severe punctuation in the Y-BOCS $(8 / 40$, lower right corner, Table I). This corresponds to the category of clinically significant symptoms (13). No significant correlation between the Y-BOCS scores and age was detected in the whole group ( $\mathrm{p}$ $=0.6$ ), but females showed a positive, marginally significant correlation: $\mathrm{r}$ (26) $0.3, \mathrm{p}$ $=0.09$.

In the primary OCD group (Table II), $45.2 \%$ were females. Males were significantly younger $(\mathrm{p}=0.01)$ and showed a non-significantly higher frequency of severe and extreme Y-BOCS categories, $(p=0.2)$. The Y-BOCS and YMRS scores were similar in both sexes ( $\mathrm{p}=0.5$ and 0.4 respectively). Collectively, $16.7 \%$ and $19 \%$ of subjects in the OCD group displayed symptoms of hypomania or mania respectively. This frequency as well as the MDQ categorization was nonsignificantly higher in males (0.4 and 0.09 respectively). A significant positive correlation between age and YMRS was detected in females: $r(19)=0.48, p=0.04$. The Kendall Tau-b correlation analysis for ordinal variables between Y-BOCS and YMRS categories did not reach statistical significance, even after controlling by sex (data not shown).

\section{DISCUSSION}

We followed a parsimonious design, by first, confirming the primary categorical diagnosis following the DSMIV-R criteria, and then evaluating the frequency and severity of the secondary diagnosis symptoms instead of diagnosing a secondary disorder.

Concerning OCS, it is tempting to consider the Y-BOCS cut-off point above the "mild" category as a proxy to OCD (16). With this criterion, we identified $20 \%$ of subjects with clinically significant OCS in our whole BD sample (Table I). Similarly, Amerio et al. (4) reported $21.7 \%$ of OCD comorbidity in BD-I subjects.

Regarding the primary OCD group, we explored bipolarity with both, a scale of symptoms severity (YMRS) and a dichotomist scale (MDQ). $16.7 \%$ and $19.0 \%$ of OCD subjects reported hypomania and mania respectively in the YMRS, and 42.9\% were positive for the whole MDQ scale (Table II). These values are considerably higher than the figures reported by Amerio et al. (4), which were $3.9 \%$ and $13.5 \%$ for BDI and BDII respectively.

A critical question is thus, which is the quantitative equivalence between "symptoms" and "disorder"? For OCD comorbidity with $\mathrm{BD}$, since our results (20\%) agree with those reported by the meta-analysis of Amerio et al. (21\%), there appears to be a good correspondence between OCD and OCS. However, in the case of comorbidity between $\mathrm{BD}$ in $\mathrm{OCD}$, we may have overestimated the diagnosis of BD. We speculate that, when using symptom scales, it is easier to interpret OCS as BDS than the opposite. However, a Swedish multigenerational register study found that the relative risk (RR) of receiving a diagnosis of $\mathrm{BD}$ after an initial diagnosis of OCD (RR: 13.7) was much greater than the risk of receiving a diagnosis of OCD after an initial diagnosis of BD (RR: 1.2) (5). This agreed with our results.

\section{Clinical vignette $\mathrm{N}^{\circ} 1$}

It is a case of a 26 year-old man in the last year of his college career; he developed a severe episode of contamination fear with the HIV virus at the age of 14. After four years he was diagnosed with OCD (DSM-IVR, with good insight) with severe relapses one or two times a year (current Y-BOCS score $=31$ ). His procrastination and avoidant behavior hampers the display of a potentially brilliant academic career, even when euthy-

Vol. 61(3): 189 - 195, 2020 
mic. His father was diagnosed with schizoaffective disorder; one brother and one sister have OCD and borderline personality disorders respectively. He identified at least 25 second to fourth-degree relatives with serious behavioral disturbances; these subjects were identified by having required psychiatric or psychological assistance.

During the last two years he presented periods of clinically significant elation or severe depression (current YMRS $=19$, classifying as hypomania). During the elation periods, he does not feel comfortably because he knows that it is an "artificial" state, and is not intellectually productive. When depressed, his OCS rather decreases, and feels relaxed but apathetic. His current treatment is cognitivebehavioral therapy, fluoxetine, lamotrigine and clonazepam, and is currently euthymic.

\section{Clinical vignette $\mathrm{N}^{\circ} 2$}

This case concerns a 23-year old male college student with intermittent OCS since his childhood. Around three months before his consultation, he started to have severe anxiety and obsessions about his body image (Y-BOCS score $=40)$. His father and mother have recurrent major depression and OC personality disorder respectively. After a moderate response to risperidone $(1 \mathrm{mg} /$ day) and alprazolam (1 mg/day), he developed significant depression; thus, we started fluoxetine $(20 \mathrm{mg} /$ day $)$. After three days of fluoxetine treatment he had dizziness, and hyponatremia was detected (plasma sodium $=126 \mathrm{mEq} / \mathrm{L}$ ). Fluoxetine was withdrawn and two-three days after, he developed a mild manic episode that remitted after 10 days of valproate administration (500 $\mathrm{mg}$ bid). We thus diagnosed OCD with moderate insight and a drug-induced manic episode. After the mood disorder, the patient and his relatives rejected pharmacological treatment and focused on psychotherapy.

This report confirms the high dimensional comorbidity between OCD and BD. The first case illustrates the high genetic load that underlies some cases of OCD (6).
Besides, this case shows that hypomanic and depressive episodes do not necessarily enhance or impair wellbeing respectively.

The second case shows the relevant genetic load of these disorders, but mainly illustrates the complexity of pharmacological treatments, such as the need of mood stabilizers, and caution with SISR-induced hypomania/mania (8). Clozapine use is also controversial in secondary OCS (17). We emphasize the need of further research in pathophysiology, drug and psychological treatment in this sensible population.

\section{Limitations}

Since our evaluation was conducted during a single interview, we could not reliably record the family history of psychopathology, the comorbidity with personality disorders, the secondary, categorical diagnosis according to the DSM-IV criteria and the long-term, time-course clinical of the comorbid disorders. These issues must be addressed in future studies.

\section{REFERENCES}

1. Goodman WK, Grice DE, Lapidus KA, Coffey BJ. Obsessive-compulsive disorder. Psychiatr Clin North Am 2014; 37: 257-67. Doi: 10.1016/j.psc.2014.06.004. PMID 25150561.

2. Merikangas KR, Akaka HS, Angst J, Greenberg PE, Robert MA, Hirschfield, MA, Petukhova M, Kessler RC. Lifetime and 12-month prevalence of bipolar spectrum disorder in the National Comorbidity Survey Replication. Arch Gen Psychiatry 2007; 64(5): 543-552. Doi: 10.1001/archpsyc. 64.5.543.

3. Mayer-Gross W, Slater E, Roth M. Clinical Psychiatry. $3^{\text {rd }}$. ed. London: Elsevier Health Sciences; 1969, pp. 129.

4. Amerio A, Stubbs B, Odone A, Tonna M, Marchesi C, Nassir Ghaemi S. Bipolar I and II disorders; a systematic review and meta-analysis on differences in comorbid obsessive-compulsive disorder. Iran $\mathrm{J}$ Psychiatry Behav Sei 2016; 10: e 3604. 
5. Cederlöf M, Lichtenstein P, Larsson H, Boman M, Rück C, Landén M, Mataix-Cols D. Obsessive-compulsive disorder, psychosis, and bipolarity: A longitudinal cohort and multigenerational family study. Schizophr Bull 2015; 41: 1076-1083. Doi: 10.1093/ schbul/sbu169.

6. Swets M, Van Dael F, Roza S, Schoevers R, Myin-Germeys I, de Haan L. Genetic risk and outcome of psychosis (GROUP). Evidence for a shared etiological mechanism of psychotic symptoms and obsessive-compulsive symptoms in patients with psychotic disorders and their siblings. PLoS ONE| Doi: 10.1371/journal.pone.0125103 June 10, 2015.

7. American Psychiatric Association. Diagnostic and Statistical Manual of Mental Disorders, Fifth Edition, DSM-5 ${ }^{\mathrm{TM}}$. Washington DC. 2013; pp. 13.

8. Sharma LP, Reddy YC. Obsessive-compulsive disorder comorbid with schizophrenia and bipolar disorder. Indian J Psychiatry 2019; 61: S140-148.

9. Amaral JA, Tamada RS, Schwartzmann AM, Shavitt RG, Miguel EC, Lafer B. Clinical expression of obsessive-compulsive disorder in women with bipolar disorder. Braz J Psychiatry 2005; 27:139-142. Doi: 10.1590/s1516-44462005 000200013.

10. Kapezinski NS, Kapezinski F. Correlates and impact of obsessive-compulsive comorbidity in bipolar disorder. Compr Psychiatry 2010; 51: 353-356. Doi: 10.1016/j.comppsych.2009.11.001.

11. Domingues-Castro MS, Torresan RC, Shavitt RG, Fontenelle LF. Bipolar disorder comorbidity in patients with obsessive-compulsive disorder: Prevalence and predictors. J Affect Disord 2019; 256: 324-330. Doi: 10.1016/j.jad.2019.06.018.
12. First MB, Spitzer RL, Gibbon M, Williams JBW. User's Guide for the Structured Clinical Interview for DSM-IV Axis I Disorders: Clinical Version. American Psychiatric Association Publishing. Washington DC, 1997.

13. Colom F, Vieta E, Martine-Aran A, García M, Reinares M, Torrent C, Goikolea JM, Banus S, Salamero M. Versión española de una escala de evaluación de la mania: validez y fiabilidad de la escala de Young. Med Clin (Bare) 2002; 119: 366-371.

14. Araque Y. Validacion de la Escala de evaluación de trastornos afectivos (MDQ) en Venezuela. Thesis. Universidad de Los Andes Medical School, Mérida, Venezuela, 2010.

15. Goodman WK, Price LH, Rasmussen SA, Mazure C, Delgado P, Heninger GR, Charney DS. The Yale-Brown Obsessive Compulsive Scale. I. Development, use, and reliability. Arch Gen Psychiatry 1989; 46 (11): 1006-1011.

16. Farris SG, MeLean CP, Van Meter PE, Simpson HB, Foa EB. Treatment response, symptom remission and wellness in obsessive-compulsive disorder. J Clin Psychiatry 2013; 74: 685-690. Doi: 10.4088/ JCP.12m07789.

17. Baptista T, Araujo, H, deLeon J. Successful clozapine augmentation after brain surgery in a subject with severe primary obsessivecompulsive disorder. J Clin Psychopharmacol 2019; 39: 86-87. 